\title{
Henry Deluy, ici et ailleurs. Une traversée d' "Action poétique», sous la direction de Julien LEFORT-FAVREAU et Saskia DELUY
}

Fabio Scotto

\section{OpenEdition}

\section{Journals}

\section{Edizione digitale}

URL: http://journals.openedition.org/studifrancesi/15847

DOI: 10.4000/studifrancesi. 15847

ISSN: 2427-5856

\section{Editore}

Rosenberg \& Sellier

\section{Edizione cartacea}

Data di pubblicazione: 1 décembre 2018

Paginazione: 532

ISSN: 0039-2944

\section{Notizia bibliografica digitale}

Fabio Scotto, «Henry Deluy, ici et ailleurs. Une traversée d'«Action poétique», sous la direction de Julien Lefort-Favreau et Saskia deluy», Studi Francesi [Online], 186 (LXII | III) | 2018, online dal 01 janvier 2019, consultato il 06 janvier 2021. URL: http://journals.openedition.org/studifrancesi/15847 ; DOI: https:// doi.org/10.4000/studifrancesi. 15847

Questo documento è stato generato automaticamente il 6 janvier 2021.

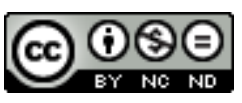

Studi Francesi è distribuita con Licenza Creative Commons Attribuzione - Non commerciale - Non opere derivate 4.0 Internazionale. 


\title{
Henry Deluy, ici et ailleurs. Une traversée d'«Action poétique», sous la direction de Julien LEFORT-FAVREAU et Saskia DELUY
}

\author{
Fabio Scotto
}

\section{NOTIZIA}

Henry Deluy, ici et ailleurs. Une traversée d' «Action poétique», sous la direction de Julien LEFORT-FAVREAU et Saskia DeluY, Montreuil, Le Temps des Cerises éditeurs, 2017, 235 pp.

1 Poeta, traduttore, bibliotecario, giornalista, animatore culturale, membro del PCF, ma anche curiosamente appassionato gastronomo, Henri Deluy, nato a Marsiglia nel 1931, è soprattutto noto nell'ambito poetico francese per avere diretto dal 1958 al 2012 la rivista «Action poétique», fondata nel 1950 da Gérald Neveu e da Jean Malrieu. Il volume, essenzialmente diviso in cinque parti, comprende, dopo una breve Ouverture (p. 7) dei curatori, che sottolinea la sua origine e struttura frammentaria, un'ampia intervista dal titolo Entretien avec Julien Lefort-Favreau (2013) (pp.9-39), nel corso della quale Henri DELUY ricostruisce con dovizia di particolari l'avventura della rivista che fu, fino alla cessazione delle pubblicazioni, la più letta di poesia in Francia, con circa mille abbonati e duecentodieci numeri pubblicati. Attraverso le vicende legate alla dialettica interna e ai vari e illustri membri del Comitato di redazione che in essa si avvicendarono (oltre ai succitati fondatori, ricordiamo, tra gli altri, Élisabeth Roudinesco, Liliane Giraudon, Jean-Jacques Viton, Jo Guglielmi), Deluy delinea anche una sua autobiografia umana e intellettuale, che coincide in larga misura con le principali vicende storiche dell'epoca post-bellica, dal rapporto conflittuale con «Tel Quel» a quello criticamente solidale con il PCF - del quale rimane membro tutt'oggi, nonostante la crisi che lo pervade da tempo e che lo ha ormai collocato ai margini del 
dibattito politico francese odierno, non senza sottrarsi al confronto con le altre riviste di poesia nate in seguito, da «Change» a «Sud», a «Banana Split», a «If», dando conto in tal modo della vitalità del dibattito poetico in Francia, così come delle implicazioni politiche che lo caratterizzano.

La matrice "meridionale" della rivista, il suo interesse manifesto per le ricerche formali delle avanguardie, che inclusero anche la poesia sonora e visiva, ne hanno fatto per decenni un baluardo militante del poietico inteso come spazio di apertura e confronto che alla "poesia" come genere, messo in discussione nel solco della nota affermazione di Denis Roche secondo la quale essa non esisterebbe, ha da sempre preferito "le poesie" come testi poetici, spesso proposti anche in traduzione, tanto da costituire una vitale vetrina di letterature maggiori e minori del mondo con un taglio fortemente internazionalizzato.

Dunque a ragione, dopo una breve Chronologie (pp.41-43), nel suo testo Là où le passé peut nous mener (pp.45-53), Anne-Renée CAILLÉ rivolge la sua attenzione all'opera poetica di Deluy mostrandone il carattere eteroclito e a tratti volutamente caotico e multiforme, data la varietà delle fonti e dei confronti ai quali si presta, volendosi anche un luogo d'accoglienza e ibridazione: «Henri Deluy fait partie de ces poètes qui ne sont pas seuls, qui incorporent les paroles de l'autre, exposent leurs influences, leurs communautés, rendent hommage presque autant qu'ils se mettent au centre de leurs pages» (p. 49).

4 E quale migliore conferma di ciò se non la sezione antologica di proprie traduzioni, «La traduction» (pp. 55-65), con versioni da Mandelstam, Cvetaeva, Akmatova, Seifert, poi seguita dalla parte più quantitativamente cospicua del volume rappresentata dal «Choix de poèmes parmi les 210 numéros d'Action poétique» (pp.71-228)? In queste pagine, nelle quali s'avvicendano alcune delle voci più significative della poesia francese degli ultimi sessant'anni, si palesa, con vivacità di forme e di approcci, un ritratto vitale di un'avventura che, quale che sia il giudizio che oggi si ritenga di darne a posteriori, rappresenta senza alcun dubbio un momento imprescindibile del poetico in Francia e in Europa nel recente mezzo secolo trascorso. Completa il volume una «Bibliographie (livres, anthologies, traductions)» (pp. 229-233). 